\title{
Rancang Bangun Kamus Digital Dramaturgi Teater Berbasis Android
}

\author{
Andi Tejawati ${ }^{1}$, Muhammad Bambang Firdaus ${ }^{2}$, Fahrul Yamani ${ }^{3}$, M Khairul Anam ${ }^{4}$ \\ 1tejawatiandi@gmail.com, ${ }^{2}$ bambangf@fkti.unmul.ac.id, ${ }^{3}$ yam.fay@gmail.com, ${ }^{4}$ khairulanam@sar.ac.id \\ ${ }^{1,2,3}$ Informatika, Universitas Mulawarman, ${ }^{4}$ Teknologi Informasi, STMIK Amik Riau
}

\begin{abstract}
Abstrak
Teater berkembang dengan baik di Indonesia sebagai sebuah karya seni, dan teater biasanya disebut sebagai drama. Untuk menyajikan pertunjukan yang berkesan, lakon dapat dilihat sebagai salah satu bentuk seni sastra, tetapi tentu saja harus memahami teknik dan metode untuk melakukan, termasuk dramaturgi dan hukum yang ada di atas panggung. Dramaturgi penting karena dapat meningkatkan kinerja seniman. Penelitian ini akan membuat kamus digital yang dapat membantu seniman belajar tentang dramaturgi. Sistem ini dikembangkan dengan menggunakan prosedur prototipe. Penyelidikan ini dilakukan dengan mempelajari literatur yang berkaitan dengan teori media pembelajaran dan jenis-jenis pengembangan aplikasi berbasis Android. Metode black box digunakan untuk menguji aplikasi ini. Hasil penelitian berupa Aplikasi Kamus Digital Berbasis Dramaturgi Android. Dari hasil pengujian dapat disimpulkan bahwa aplikasi ini dikembangkan untuk mengajarkan para pelaku seni memahami istilahistilah penulis naskah. Dimungkinkan juga untuk menggunakan aplikasi.
\end{abstract}

Kata kunci: Teater, Dramaturgi, Kamus Digital

The theater is well-developed in Indonesia as a work of art, and it is usually referred to as a drama. In order to present a memorable show, the play can be seen as a form of literary art, but one must, of course, understand the techniques and methods to perform, including dramaturgy and existing laws on stages. Dramaturgy is essential because it can improve the performance of artists. This research will create a digital dictionary that can help artists learn about dramaturgy. This system is developed using the prototype procedure. This investigation was carried out by studying literature relating to media learning theory and the types of development of Android-based applications. The black box method is used to test this application. The study results are a Digital Dictionary Application based on Android Dramaturgy. It can be concluded from the test results that this application was developed to teach art actors how to understand playwright terms. It is also possible to use the application.

Keywords: Theater, Dramaturgy, Digital Dictionary

\section{Pendahuluan}

Bagi masyarakat di sekitar kita, khususnya yang memiliki keterampilan teater, keberadaan teater sebagai karya seni yang hadir di Indonesia sudah tidak asing lagi. Teater selalu menampilkan aspek-aspek kehidupan sosial yang menarik dan kritis, bahkan memiliki kecenderungan untuk mengkritik secara konstruktif dan bereaksi terhadap perkembangan kehidupan di masyarakat. Teater biasanya diartikan di Indonesia sendiri sebagai seni pertunjukan drama [1]. Pengajaran hal-hal yang legal dan dramatis adalah dramaturgi [2]. Istilah dramaturgi melibatkan serapan atau pungutan teater berbahasa Belanda, yang mencakup pengajaran seni drama atau seni atau teknik teater [3]. Dramaturgi, jika diringkas secara singkat, memandang kehidupan sebagai panggung di mana orang-orang memainkan peran terbaiknya sehingga penonton dapat menikmatinya dengan baik [4]. Selain unsur manusia sebagai pemain atau roleholder dalam teater, tampaknya sistem dan teknik pentas saat ini harus dikaitkan dengan perkembangan teknologi modern [5].

Tidak diragukan lagi bahwa Erving Goffman adalah tokoh yang paling berpengaruh dan menonjol dalam teori dramaturgi saat ini. Sebuah sandiwara panggung adalah analogi Goffman untuk kehidupan. Orang-orang adalah aktor di atas panggung, dan situasi atau latar dalam kehidupan sehari-hari dapat 
SIMKOM, Vol. 6, No. 2, Juli 2021

ISSN: 2715-906X (Online)

\section{doi) $10.51717 /$ simkom.v6i2.56}

dibandingkan dengan panggung untuk pertunjukan. Ini disebut dramaturgi. Menentukan bagaimana Anda akan memposisikan diri Anda, apa yang akan Anda katakan, dan tindakan apa yang akan Anda ambil [6]. Ada panggung depan dan belakang panggung dalam kehidupan sosial, menurut Goffman. Individu dapat menata atau melakukan peran formal di panggung depan, dibagi menjadi kepribadian (Personal Front) dan spasial (Pengaturan). Ini termasuk bahasa verbal dan nonverbal aktor, sedangkan spasial mengacu pada lokasi atau situasi di mana aktor tampil. Dari sudut pandang penonton, backstage adalah area tersembunyi (audience). Karena rahasia aktor akan dibobol jika penonton masuk ke belakang panggung, aksi panggung akan lebih menantang untuk dilakukan [7].

Dalam hal dramaturgi, tujuannya adalah untuk memberikan gambaran tentang peristiwa lakon yang dapat menarik penonton ke panggung drama. Menurut Eugene Barba, dramaturgi adalah akumulasi dari tindakan yang tidak terbatas pada gerakan aktor tetapi juga tindakan yang berkaitan dengan adegan, musik, cahaya dan vokal aktor, serta efek suara dan objek yang digunakan dalam pertunjukan [8].

Pentingnya dramaturgi, karena mengubah pemahaman kita dan kemungkinan berkembangnya teater dan teater atau seni pertunjukan lebih lanjut. Drama juga dapat meningkatkan apa yang kita lakukan untuk kita (aktor). Dalam pembelajaran dan pemahaman tentang istilah-istilah dramaturgi, beberapa pelaku seni terkadang kesulitan untuk menemukan sumber literatur. Sehingga tidak sedikit yang mengalami kesulitan mengekspresikan karya dalam bentuk pertunjukan, terlebih para pegiat seni generasi muda. Maka dari itu penulis berinisiatif mengembangkan sebuah Kamus Dramaturgi Teater Berbasis Android, dengan tujuan untuk memudahkan para pelaku seni pertunjukan dalam memahami istilah-istilah dramaturgi yang akan membantu meningkatkan kreatifitas pada proses pembuatan sebuah karya pertunjukan.

\section{Metode}

\subsection{Metode Pengembangan Sistem}

Metode prototyping merupakan paradigma baru dalam pembuatan atau pengembangan perangkat lunak, dan digunakan dalam pengembangan perangkat lunak [9]. Pengembangan atau pembuatan perangkat lunak telah mengalami revolusi karena metode ini, yang didasarkan pada sistem sekuensial yang dikenal sebagai Metode Waterfall [10] [11]. Pendekatan prototype/prototyping memungkinkan klien untuk memberikan masukan dan kritik [12] [13], sehingga menghasilkan produk perangkat lunak yang sesuai dengan kebutuhan dan keinginannya. Sampai konsensus tercapai, perubahan perangkat lunak dapat dilakukan berulang kali.

Penelitian ini dilakukan dengan menggunakan metode pengembangan sistem yaitu prototype yang dipilih [14] [15]. Tujuan pembuatan prototipe untuk pengembang sistem adalah untuk mengumpulkan informasi pengguna sehingga pengguna dapat berinteraksi dengan model prototipe yang dikembangkan [16] [17]. Prototipe memungkinkan interaksi pengguna-ke-sistem sehingga ketidakcocokan antara pengembang dan pengguna dapat diatasi [18].

Premis dari ide ini adalah untuk membuat prototipe secepat mungkin, bahkan dalam semalam, sehingga pengguna menerima umpan balik yang memungkinkan pengerjaan ulang prototipe dengan cepat [19] [20]. Dengan melihat gambar yang jelas, metode prototype dapat menjelaskan kebutuhan pengguna secara detail [13] [21]. Prototipe sendiri bertujuan agar pengguna dapat memahami alur proses sistem dengan tampilan dan simulasi yang siap pakai [22] [23]. Berikut langkah-langkah yang dilakukan untuk mengembangkan sistem menggunakan metode prototype. 
SIMKOM, Vol. 6, No. 2, Juli 2021

ISSN: 2715-906X (Online)

doi) $10.51717 /$ simkom.v6i2.56

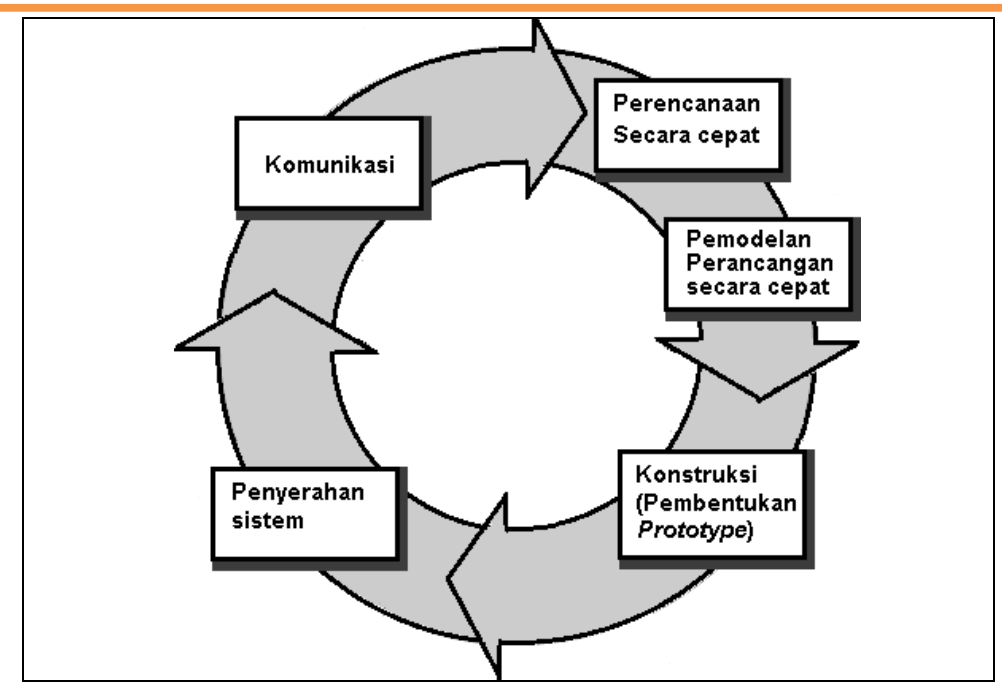

Gambar 1. Metode Prototype

Tahap pengembangan pada model prototype ini ialah sebagai berikut:

1. komunikasi: Tahapan awal untuk mendapatkan informasi dan juga menghimpun data apa saja yang diperlukan dalam pengembangan aplikasi.

2. Perencanaan dan Pemodelan: Selanjutnya membuat sebuah perencanaan sistem berdasarkan hasil dari tahap komunikasi dan pemodelan antar muka dari sistem yang akan dibangun.

3. Konstruksi: Setelah mengetahui tujuan dan rancangan, maka prototype mulai dikerjakan.

4. Penyerahan Sistem: sistem akan diserahkan kepada pengguna untuk mendapatkan timbal- balik agar dapat di evaluasi apakah sistem sudah sesuai seperti yang diharapkan.

\section{Hasil dan Pembahasan}

\subsection{Hasil Pengembangan Aplikasi}

Pada tahapan ini akan menjelaskan tentang tampilan (interface) aplikasi dan layout. Hasil pengembangan aplikasi dapat dilihat sebagai berikut

\subsubsection{Tampilan Halaman Utama}

Halaman utama merupakan halaman yang akan tampila ketika mengakses sistem. Pada halaman ini terdapat logo aplikasi dan pilihan menu antara lain Library, About, dan Exit. Tampilan halaman utama dapat dilihat pada Gambar 2.

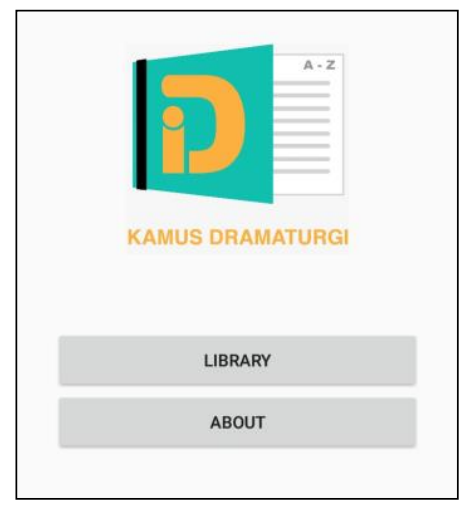

Gambar 2. Tampilan Menu Utama 
SIMKOM, Vol. 6, No. 2, Juli 2021

ISSN: 2715-906X (Online)

doi) $10.51717 /$ simkom.v6i2.56

\subsubsection{Tampilan Library}

Halaman library adalah halaman yang akan menampilkan daftar istilah secara berurutan sesuai dengan abjad, dan bisa diakses secara langsung, serta terdapat kolom pemcarian yang bisa diakses untuk membantu pengguna melakukan pencarian istilah yang diinginkan. Tampilan halaman library dapat dilihat pada Gambar 3 dan Gambar 4.

\begin{tabular}{|l|}
\hline$\leftarrow \quad$ Dramaturgi \\
\hline Cari lstilah \\
\hline Abstrak \\
Absurd \\
Adegan \\
Agon \\
Akting \\
Aktor \\
Aktris \\
Alienasi \\
Anabasis \\
Antiklimaks \\
\hline
\end{tabular}

Gambar 3. Tampilan Menu Library

\begin{tabular}{|l|}
\hline$\leftarrow$ Dramaturgi \\
\hline Cari Istilah \\
\hline Upstage \\
Verbal \\
Veritisme \\
Visual \\
Vokal \\
Volume \\
Wawancang \\
Wayang Golek \\
Wayang Kulit \\
Wayang Orang \\
\hline
\end{tabular}

Gambar 4. Tampilan Menu Library 
SIMKOM, Vol. 6, No. 2, Juli 2021

ISSN: 2715-906X (Online)

doi) $10.51717 /$ simkom.v6i2.56

\subsubsection{Tampilan Halaman Terjemahan}

Halaman terjemahan adalah halaman yang akan ditampilkan ketikan pengguna memilih salah satu dari daftar istilah yang ada, pada halam ini pengguna dapat melihat penjelasan dari istilah tersebut. Tampilan halaman terjemahan dapat dilihat pada Gambar 5.

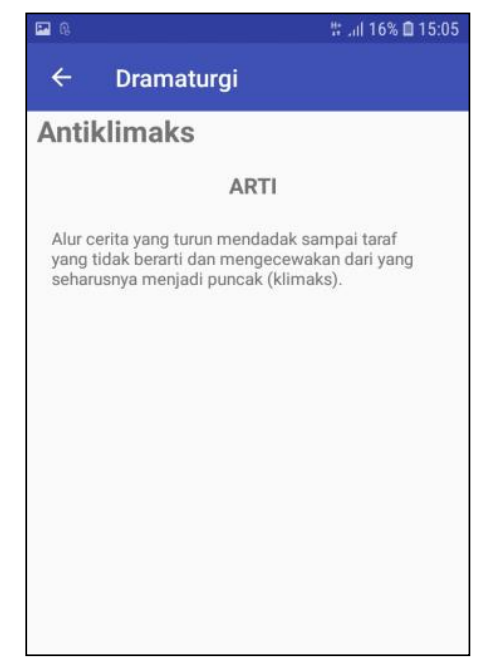

Gambar 5. Tampilan halaman Terjemahan

\subsubsection{Tampilan Halaman About}

Halaman about merupakan halaman yang akan menampilkan informasi tentang aplikasi yang bisa dilihat oleh pengguna. Tampilan halaman about dapat dilihat pada gambar.

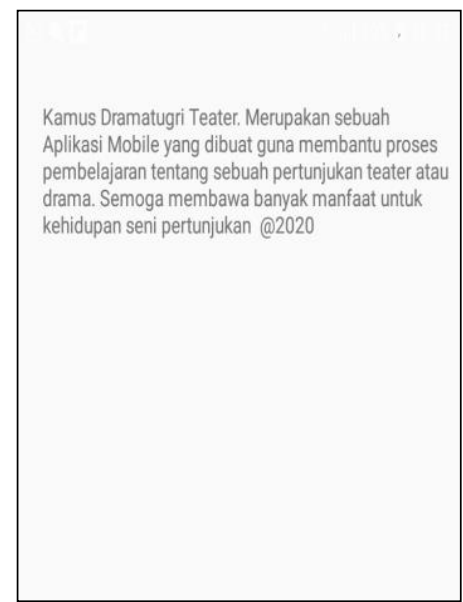

Gambar 6. Tampilan halaman About

\subsection{Pengujian Aplikasi}

Pengujian aplikasi ditujukan untuk mengetahui tingkat keberhasilan system yang dirancang telah sesuai dengan yang ingin dicapai.

\subsubsection{Pengujian Sistem}

Metode blackbox digunakan untuk pengujian sistem. Pendekatan blackbox berfokus pada persyaratan fungsional perangkat lunak [24] [25]. Pengujian dilakukan dengan memeriksa fungsi-fungsi yang sudah tersedia. Tes yang dilakukan meliputi: 
SIMKOM, Vol. 6, No. 2, Juli 2021

ISSN: 2715-906X (Online)

$10.51717 /$ simkom.v6i2.56

Tabel 1. Pengujian Sistem

\begin{tabular}{clll}
\hline No & \multicolumn{1}{c}{ Komponen Pengujian } & \multicolumn{1}{c}{ Hasil Pengujian } & \multicolumn{1}{c}{ Kesimpulan } \\
\hline 1 & $\begin{array}{l}\text { Memilih menu library pada } \\
\text { halaman utama }\end{array}$ & $\begin{array}{l}\text { Sistem akan menuju halaman } \\
\text { library yang berisi istilah- } \\
\text { istilah. }\end{array}$ & $\begin{array}{l}\text { Sistem menampilkan istilah } \\
\text { secara berurutan sesuai abjad }\end{array}$ \\
2 & Memilih istilah yang ada & $\begin{array}{l}\text { Sistem akan menampilkan } \\
\text { halaman terjemahan }\end{array}$ & $\begin{array}{l}\text { Sistem menampilkan pengertian } \\
\text { dari istilah yang dipilih }\end{array}$ \\
3 & $\begin{array}{l}\text { Memasukkan kata pada } \\
\text { kolom pencarian pada } \\
\text { halaman library }\end{array}$ & $\begin{array}{l}\text { Sistem akan menampilkan } \\
\text { kata yang sesuai dengan yang } \\
\text { dicari }\end{array}$ & $\begin{array}{l}\text { Sistem hanya menampilkan } \\
\text { istilah yang sesuai dengan kata } \\
\text { yang dimasukkan pada kolom } \\
\text { pencarian }\end{array}$ \\
\hline
\end{tabular}

\subsubsection{Pengujian Kelayakan}

Pengujian kelayakan ini didasarkan pada penilaian pengguna. Total responden dalam pengujian pada aplikasi kamus dramaturgi teater ini berjumlah 20 orang dari kalangan pelaku seni. Penilaian dilakukan dengan mengisi kuesioner setelah pengguna mencoba aplikasi tersebut. Adapun hasil dari penilaian pengguna sebagai berikut:

Tabel 2. Penilaian Pengguna

\begin{tabular}{|c|c|c|c|c|c|c|c|}
\hline \multirow[b]{2}{*}{ No } & \multirow[b]{2}{*}{ Pertanyaan } & \multicolumn{5}{|c|}{ Persentase Jawaban (\%) } & \multirow[b]{2}{*}{ Total } \\
\hline & & $\begin{array}{l}\text { Sangat } \\
\text { Setuju }\end{array}$ & Setuju & $\begin{array}{l}\text { Tidak } \\
\text { Tahu }\end{array}$ & $\begin{array}{l}\text { Tidak } \\
\text { Setuju }\end{array}$ & $\begin{array}{l}\text { Sangat } \\
\text { Tidak } \\
\text { Setuju }\end{array}$ & \\
\hline 1 & Tampilan aplikasi sederhana dan baik & $25 \%$ & $50 \%$ & $15 \%$ & $10 \%$ & $0 \%$ & $100 \%$ \\
\hline 2 & Kemudahan dalam menggunakan aplikasi & $55 \%$ & $45 \%$ & $0 \%$ & $0 \%$ & $0 \%$ & $100 \%$ \\
\hline 3 & Istilah pada aplikasi mudah untuk dipahami & $50 \%$ & $40 \%$ & $5 \%$ & $5 \%$ & $0 \%$ & $100 \%$ \\
\hline 4 & $\begin{array}{l}\text { Aplikasi ini akan membantu untuk proses } \\
\text { kreatif pelaku seni }\end{array}$ & $75 \%$ & $25 \%$ & $0 \%$ & $0 \%$ & $0 \%$ & $100 \%$ \\
\hline 5 & $\begin{array}{l}\text { Aplikasi ini akan membantu pada proses } \\
\text { pembelajaran }\end{array}$ & $65 \%$ & $35 \%$ & $0 \%$ & $0 \%$ & $0 \%$ & $100 \%$ \\
\hline 6 & $\begin{array}{l}\text { Istilah yang ada pada aplikasi ini cukup } \\
\text { lengkap }\end{array}$ & $45 \%$ & $40 \%$ & $15 \%$ & $0 \%$ & $0 \%$ & $100 \%$ \\
\hline
\end{tabular}

Berdasarkan dari hasil implementasi dan pengujian yang telah dilakukan, Aplikasi Kamus Dramaturgi Teater yang dibangun sudah berjalan cukup baik sebagaimana yang diharapkan penulis.

\section{Kesimpulan dan Saran}

Berdasarkan dari pembahasan yang telah dijelaskan sebelumnya, maka dapat ditarik kesimpulan bahwa penelitian ini menghasilkan satu aplikasi kamus dramaturgi teater yang dapat memberikan pengetahuan mengenai istilah-istilah yang ada dalam lingkup kesenian khususnya teater. Dari pembahasan dan kesimpulan dalam penelitian ini, saran untuk pengembangan lebih lanjut adalah penambahan gambar atau ilustrasi pada setiap istilah yang terdapat pada kamus digital ini, agar lebih mempermudah dalam memahami istilah tersebut. Menambah jumlah istilah serta lingkup pembahasan agar tidak hanya terpaku pada teater saja. 
SIMKOM, Vol. 6, No. 2, Juli 2021

ISSN: 2715-906X (Online)

$10.51717 /$ simkom.v6i2.56

\section{Daftar Pustaka}

[1] Y. Tresnawati, M. Rahayu, and M. Husen, "Tinder and Impact on Personal and Social Life," vol. 219, no. Icpc, 2019, doi: 10.2991/icpc-18.2019.19.

[2] V. Versigny, "Memahami Impression Management pada Selebsmule,” J. Egaliter, 2018.

[3] A. S. Helm, "Organizational User Participation: From Dramaturgy to Pedagogy in working with vulnerable young people A Bio-psycho-social perspective," pp. 206-214, 2017.

[4] R. A. Shofiana and Juariyah, "Impression Management Pengguna Aplikasi Tik Tok (Analisis Dramaturgi Erving Goffman Bagi Siswa SMA/SMK di Kecamatan Ambulu),” J. Fisipol, 2019.

[5] R. Dewi and P. A. Janitra, "Dramaturgi Dalam Media Sosial: Second Account di Instagram Sebagai Alter Ego,” J. Ilmu Komun., vol. 8, no. 3, pp. 340-347, 2018.

[6] A. W. Anindhita., "Dramaturgi Dibalik Kehidupan Social Climber," J. Komun. dan Bisnis, vol. VI, no. 1, pp. 1-11, 2018.

[7] P. E. Haes and N. I. Pratiwi, "Pagelaran Budaya Jepang Cosplayer Dalam Perspektif Dramaturgi," J. Educ. Hum. Soc. Sci., vol. 2, no. 2, pp. 245-253, 2019, doi: 10.34007/jehss.v2i2.90.

[8] J. K. Wardhani, "Dramaturgi Ludruk Karya Budaya Mojokerto Jawa Timur Lakon Sarip Tambak Oso," J. Satwika, vol. 3, no. 1, p. 27, 2019, doi: 10.22219/satwika.vol3.no1.27-42.

[9] M. B. Firdaus, E. Budiman, Haviluddin, M. Wati, H. J. Setyadi, and H. S. Pakpahan, "An openness of government website content using text analysis method," Int. J. Eng. Adv. Technol., vol. 8, no. 5, pp. 1461-1466, 2019, doi: 10.35940/ijeat.E1214.0585C19.

[10] M. B. Firdaus, E. Budiman, M. F. Anshori, J. Teknologi, and U. Mulawarman, "Evaluasi Skema Panduan Game Berbasis Motion Graphic Animation Pada Esports Bergenre Multiplayer Online Battle Arena," JURTI Univ. Mulawarman, vol. 4, no. 1, p. 36, 2020.

[11] M. Kristian, I. Fitri, and A. Gunaryati, "Implementation of Augmented Reality for Introduction To Android Based Mammalian Animals Using The Marker Based Tracking Method," JISA(Jurnal Inform. dan Sains), vol. 3, no. 1, pp. 1-6, 2020, doi: 10.31326/jisa.v3i1.623.

[12] M. B. Firdaus, "Pengembangan Alat Ukur Keterbukaan Informasi Publik pada Situs Web Pemerintah Studi Kasus Kabupaten Kutai Kartanegara,” J. Ilm. Ilmu Komput., vol. 3, no. 1, pp. 713, 2017.

[13] N. Leelawat, A. Suppasri, P. Latcharote, Y. Abe, K. Sugiyasu, and F. Imamura, "Tsunami evacuation experiment using a mobile application: A design science approach," Int. J. Disaster Risk Reduct., 2017, doi: 10.1016/j.ijdrr.2017.06.014.

[14] M. B. Firdaus, E. Budiman, joan angelina Widians, novel maringan Sinaga, S. Fadli, and F. Alameka, "Augmented Reality for Office and Basic Programming Laboratory Peripheral," 2018 2nd East Indones. Conf. Comput. Inf. Technol., vol. 2, no. 2, pp. 41-45, 2018.

[15] N. Dengen, H. S. Pakpahan, G. F. Putra, M. B. Firdaus, R. Wardhana, and A. Tejawati, "An Augmented Reality Model Physical Transformation Learning," ICEEIE 2019 - Int. Conf. Electr. Electron. Inf. Eng. Emerg. Innov. Technol. Sustain. Futur., pp. 255-259, 2019, doi: 10.1109/ICEEIE47180.2019.8981444.

[16] D. Karim and H. B. Santoso, "Perancangan Dan Usability Evaluation Prototipe Informasi Akademik Menggunakan Metode Rapid Application Development," J. Ilm. Ilk. - Ilmu Komput. Inform., vol. 2, no. 2, pp. 68-79, 2019, doi: 10.47324/ilkominfo.v2i2.33.

[17] A. Tejawati, M. B. Firdaus, M. N. Ihwan, F. Alameka, and M. K. Anam, "Prototipe Media Pembelajaran Rambu Lalu Lintas Berbasis Android," Metik J., vol. 5, no. 1, pp. 12-18, 2021, doi: 10.47002/metik.v5i1.210.

[18] R. Spicer, J. Anglin, D. M. Krum, and S. L. Liew, "REINVENT: A low-cost, virtual reality braincomputer interface for severe stroke upper limb motor recovery," Proc. - IEEE Virtual Real., pp. 385-386, 2017, doi: 10.1109/VR.2017.7892338.

[19] C. H. Tsai and J. Y. Huang, "Augmented reality display based on user behavior," Comput. Stand. Interfaces, vol. 55, pp. 171-181, 2018, doi: 10.1016/j.csi.2017.08.003.

[20] H. Ro, J. H. Byun, I. Kim, Y. J. Park, K. Kim, and T. D. Han, "Projection-Based Augmented Reality Robot Prototype with Human-Awareness," ACM/IEEE Int. Conf. Human-Robot Interact., vol. 2019-March, pp. 598-599, 2019, doi: 10.1109/HRI.2019.8673173. 
SIMKOM, Vol. 6, No. 2, Juli 2021

ISSN: 2715-906X (Online)

doi) $10.51717 /$ simkom.v6i2.56

[21] M. B. Firdaus, N. Puspitasari, E. Budiman, J. A. Widians, and N. Bayti, "Analysis of the effect of quality mulawarman university language center websites on user satisfaction using the webqual 4.0 method," Proc. ICAITI 2019 - 2nd Int. Conf. Appl. Inf. Technol. Innov. Explor. Futur. Technol. Appl. Inf. Technol. Innov., pp. 126-132, 2019, doi: 10.1109/ICAITI48442.2019.8982143.

[22] A. Fazel and A. Izadi, "An interactive augmented reality tool for constructing free-form modular surfaces," Autom. Constr., vol. 85, no. October 2016, pp. 135-145, 2018, doi: 10.1016/j.autcon.2017.10.015.

[23] B. Cahyono, M. B. Firdaus, E. Budiman, and M. Wati, "Augmented Reality Applied to Geometry Education," 2018 2nd East Indones. Conf. Comput. Inf. Technol., vol. 2, no. 2, pp. 299-303, 2018.

[24] A. Tejawati, E. K. Pradana, M. B. Firdaus, F. Suandi, L. Lathifah, and M. K. Anam, "Pengembangan Video Dokumenter 'Wanita Dan Informatika' Di Lingkungan Fkti Universitas Mulawarman," J. Inform. dan Rekayasa Elektron., vol. 2, no. 2, p. 72, 2019, doi: 10.36595/jire.v2i2.121.

[25] N. Puspitasari, M. B. Firdaus, C. A. Haris, and H. J. Setyadi, "An application of the UTAUT model for analysis of adoption of integrated license service information system," Procedia Comput. Sci., vol. 161, pp. 57-65, 2019, doi: 10.1016/j.procs.2019.11.099. 